\begin{tabular}{|l|l|}
\hline Postprint Version & 1.0 \\
\hline Journal website & http://portal.acm.org/citation.cfm?id=1671983 \\
\hline Pubmed link & \\
\hline DOI & $10.1504 /$ IJBIS.2010.030627 \\
\hline
\end{tabular}

This is a NIVEL certified Post Print, more info at http://www.nivel.eu

\title{
The conditional benefits of early user involvement at employee self-service applications in four Dutch ministries
}

\author{
RONALD BATENBURG ${ }^{1}$, GERWIN KOOPMAN ${ }^{2}$
}

${ }^{1}$ Department of Information and Computing Sciences Utrecht University P.O. Box 80089, 3508 TB Utrecht, The Netherlands E-mail: r.s.batenburg@cs.uu.nl

${ }^{2}$ Syntess Software P.O. Box 127, 4300 AC Zierikzee, The Netherlands E-mail: koopmang@hotmail.nl

\begin{abstract}
:
User participation and user involvement is generally accepted as one of the important factors for IS success. In this paper, several types of early end-user involvement are distinguished and empirically explored through four case studies. The cases concern four Dutch governmental organisations (ministries) that have recently deployed an Employee Self-Service (ESS) application. Interviews were held with developers, project managers and users.

It was found that the perceived success of the ESS-systems within the ministries is not directly related to the type or number of user involvement methods applied. Benefits of user participation are conditional, i.e., dependent on time- and culture-related factors. In particular, expectancy management about the project milestones is important, and so is the belief among employees that they can easily use the self-service applications without much support from the HR departments.
\end{abstract}

\section{INTRODUCTION}

From both research and practice, there appears to be a common belief about the positive effects of user participation and user involvement on the success of information systems (IS) deployment (cf. Shaw et al., 2005; DeLone and McLean, 1992; DeLone and McLean, 2003). More specifically, the statement is that the sooner the end-user is involved, the more beneficial this will be for the organisational adoption and implementation of IS (Noyes et al., 1996; Chatzoglou and Macaulay, 1996; Blackburn et al., 2000). Lin and Shao (2000) found a significant relationship between user participation and IS success, but also found that the context should be taken into account.

Both user participation and system success can be directly and indirectly influenced by other factors. A related issue, is what method and target group to select in applying (early) user involvement or participation (cf. Grudin, 1991). To what level should organisations invest in this involvement, and when do costs exceed the benefits? Is it most effective to test prototypes with experienced or inexperienced users? What tools can motivate users without making promises about adaptability that cannot be realised? Should participation imply co-design in cognitive heuristic evaluation (cf. Wharton et al., 1992) or should it be limited to usability testing (cf. Mantei and Teorey, 1988; Nielsen and Mack, 1994)? In this paper we present the results of a study on end-user involvement in four different Dutch governmental institutions. All these four Dutch governmental organisations (ministries) have recently implemented Employee Self-Service (ESS) 
applications (i.e., e-HRM). Through semi-structured and topic interviews, the type of end-user involvement is defined, as well as the perceived success of the deployment.

Based on case comparison, this enables us to explore the relationship between the method of user involvement and IS success. It should be realised on one hand, that our conclusions are scoped to the specific context of a public organisation and employee self-service applications. Still, this is a highly relevant empirical domain because governmental organisations (such as ministries) employ large number of employees, and e-HRM applications apply to all types of potential end-users. The case studies therefore clearly address the challenges of making the right selection of users and participation methods in relation to the deployment success.

\section{THEORY}

User satisfaction is considered a useful measure in evaluating the success of information systems (cf. Ives et al., 1983). In their study, Lin and Shao (2000) found that getting users involved in the development process improves their attitude towards the system and enhances their perception of its importance and relevance. In a survey of 200 production managers, Baroudi et al. (1986) also found positive correlations between user involvement, user information satisfaction and system usage. User involvement was conceptualised as activities during the development that enabled the users to influence the development. Interviewing users and developers from 151 projects, McKeen and Guimaraes (1997) also found a positive and significant relationship between user participation and user satisfaction. They noted that projects concerning systems or tasks with a high complexity called for more user participation. Finally, Kensing and Blomberg (1998) state that the participation of end-users is "seen as one of the preconditions for good design" (see also Shapiro, 2005). The workers have information about the working environment and organisation, which designers logically do not always possess.

Combining the domain knowledge of the workers and the technical knowledge of the designers is considered a foundation for the development of a useful application (Kensing and Blomberg, 1998). According to Kujala (2003), user involvement can be seen as a general term. He refers to Damodaran (1996) who suggests a continuum from informative to consultative to participative. Other researchers, however, suggest that there is a difference between user involvement and user participation (McKeen et al., 1994). User participation will then be the "assignments, activities, and behaviours that users or their representatives perform during the systems development process” (Barki and Hartwick, 1989). User involvement can be regarded as "a subjective psychological state reflecting the importance and personal relevance that a user attaches to a given system” (Barki and Hartwick, 1989).

User participation can take on a number of forms during the development of a software product. Kujala (2003) suggests four main approaches:

1. User-centred design recommended the early focus on users and direct contact between development team and end-users (Gould and Lewis, 1985). This implies doing interviews and discussions with end-users, even before any design has been made. People should be observed when performing tasks, both in the present situation and in the prototypes that are developed during the project. Also the design should be iterative; this could, for instance, be realised by using prototypes that can be reviewed by users.

2. Participatory design is considered to be a design philosophy instead of a methodology (Cherry and Macredie, 1999). It is not prescriptive and therefore the set of techniques that could be used should be considered open-ended. The approach does have some identifiable principles, however. Firstly it aims at the production of information systems that improve the work environment. Secondly, users should be actively involved in each stage of the development; and finally, the development should be under constant review (iterative design). Cherry and Macredie (1999) also mention four important techniques, cooperative prototyping being the main technique. The other techniques are brainstorming, workshops and organisational gaming.

3. Ethnography consists of observing and describing the activities of a group, in an attempt to understand these activities (Littlejohn, 2002). In the design of information systems, it is defined as developing "a thorough understanding of current work practices as a basis for the design of computer support” (Simonsen and Kensing, 1997). The reason for this is the occurrence of differences in what users say they do, and what they actually do (Nielsen, 1993). The approach is 
descriptive of nature, is from a member's point of view, and takes place in natural settings; behaviours should therefore be explained from their context (Blomberg et al., 1993). A typical method of ethnography is observing end-users while they perform their daily work.This can be done by following them in their work, with designers being present at the office, or recording the tasks on video and then analysing this footage later on.

4. Contextual design is similar to ethnography, and helps a cross-functional team to agree on what users need and design a system for them (Beyer and Holtzblatt, 1999).The approach focuses on the improvement of the current way of working within an organisation. It is not only limited therefore, to the design of a system, but also incorporates redesigning the work processes. Users are the main source of data to support decisions on what developments should take place.

Specific methods to obtain information from users are (paper) prototyping and contextual inquiry. The latter method is a combination of observing users and interviewing them at the same moment (Beyer and Holtzblatt, 1999).

Co-development, ethnographic methods and contextual inquiry are participatory approaches that are located early in the development cycle (Muller, 2001). Most of the approaches actually span the entire development process. The three basic methods that can be extracted from these design approaches can be summarised as:

1. testing, through interviews and discussions with end-users, brainstorming, workshops, organisational gaming

2. use research, through observing users when performing tasks of daily work or contextual inquiry

3. prototyping, through cooperative prototyping or paper prototyping.

In addition to these methods, another approach is to define a few 'personas' for early user involvement (Grudin, 1991). A persona is defined as "an archetype of a user that is given a name and a face, and it is carefully described in terms of needs, goals and tasks" (Blomquist and Arvola, 2002). This can be useful in organisations that have large groups of users, which makes it tricky to randomly select a small selection from the total group. It is also recommended to have the development team working on location of the enduser to achieve easy access for (planned or ad hoc) user participation and involvement.

\section{CASE STUDIES: EMPLOYEES' SELF-SERVICES APPLICATION DEVELOPMENT AT FOUR DUTCH MINISTRIES}

ESS systems represent one of the fast developing trends in the domain of e-HRM (Strohmeier, 2007; Ruël et al., 2004). Konradt et al. (2006) define ESS system as a "corporate web portal that enables managers and employees to view, create and maintain relevant personnel information”. ESS systems are designed to automate tasks that are normally done by the organisations' HR department. In her study on three successful ESS implementations, Fister Gale (2003) described that reducing the workload of these personnel departments is a major reason for implementation. For instance, changing personal information of employees in often several databases normally had to be done by HR employees. This can now be done by employees themselves by filling in web-based forms, resulting in (real-time) updates of the databases of the HR systems. The web-based nature of the ESS also offers the possibility to significantly decrease the paperwork that needs to be handled. However, the benefits are not only on the organisations' side; employees also profit from the implementation of ESS. They have instant access to information and the effort needed for certain transactions, such as expense claims, is reduced. Managers also benefit from the up-to-date information and easy access to - for instance - reports, resulting in a better overview of their resources.

At first sight, there seems to be a conflict in combining user participation and/or user involvement with the deployment ESS. One main reason is that e-HRM systems and Shared Service Centres (SSCs) are mainly adopted to increase efficiency and productivity (Janssen and Joha, 2006). Involving users actually puts extra time pressure on IT projects, because it takes extra resource investments from the organisation. For public organisations in particular, planning and budgets are mostly fixed and based on long-term planning and political negotiation. Owing to political factors such as a cabinet's term, IT projects in governmental organisations sometimes face the pressure to be delivered on time and within budget for seemingly opportunistic reasons (Grudin, 1991). In addition, early user involvement might not match with the bureaucratic and centralised culture that is dominant in large public organisations such as ministries. This 
type of culture might actually hinder a participative approach to IS/IT deployment. It is often underestimated how strongly organisational culture determines both software deployment, as well as the software development process itself (cf. Iivari, 2006).

The next four case studies all provide insights into the barriers and opportunities of early user involvement during the development of an ESS, at four Dutch ministries. All case studies were executed in 2007 and were based on desk research and interviews, which were held with the key players of the ESS development and deployment process.

\subsection{Case study 1: The Ministry of the Interior and Kingdom Relationships}

In 2002, the Ministry of the Interior and Kingdom Relationships developed the Self-Service application 'Emplaza' (a combination of the words 'Employability' and 'Plaza'). This self-service human resources application was used by approximately 5500 civil servants within the Ministry of the Interior and Kingdom Relationships. The application was also used by the Ministry of Agriculture, Nature and Food Quality and the Ministry of Economic Affairs, resulting in a total number of about 17000 users. The software supports up to $20 \mathrm{HR}$-processes, for instance, applying for leave or filing an appraisal conversation. The application was a web application, that functioned as layer build on top of the actual administrative IT system. It was built and managed by an external party.

At the time of the interviews, a new release of the application (version 4.3) was under development. The new release has taken more than a year to develop because of some important differences with previous situations. First of all, the builders were new to the project and therefore the advantage of having worked together (as with previous releases) was lost. Second, release 4.3 can be considered larger and more extended in words of number of functionalities. As a result, testing the application took a considerable amount of extra time.

For the development of the new releases, key users or super users were selected to participate. These civil servants had a lot of knowledge about the process the application was supposed to support. By interviewing them, they explicated the way the process to be executed was determined. A next step was to establish which forms should be available to support tasks within the process. After that, the next task was to find out how the forms and workflow should look like in Emplaza. When agreement was reached on these issues, the functional designs were created by the software developer. The key users were very involved in the business rules that needed to be implemented in the system. They were also asked to judge other aspects, such as the look and feel of the user interface and the performance of the application. To do this, test scripts were used for every step and part of the new functionality to support comments on all new developments. Members of the HR self-service project team also tested the application by looking at it from the viewpoint of the new, 'future' user. They specifically paid attention to the help texts that were created for the endusers to guide them through certain tasks.

A number of criteria were used in selecting employees to participate in the development of the new release. Participants had to have substantial knowledge and experience in the field concerning the process at hand. Furthermore, they had to be available to cooperate, i.e., they had to be freed from their normal tasks. Finally, they also had to be able to think constructively about the new functionality. Quite interestingly, the programme managers also tried to include two 'camps' in the early user involvement: those who are sceptical of ICT and those who feel positive about ICT. Most of the end-users came from the central apparatus of the Ministry that was located close to the test location.

\subsection{Case study 2: The Ministry of Internal Affairs}

In July 2003 the Dutch cabinet chose to start the establishment of a SSC called 'P-Direkt', including a HRM application SSC for personnel registration and salary administration. P-Direkt should lead to a more efficient HR arm of the government itself, i.e., the Ministry of Internal Affairs. The project consisted of two parts: joining administrative HR tasks and the implementation of digital self-service. In contrast to the Emplaza 4.3 release, this was an entirely new application. It was built using mostly standard functionalities of SAP. If necessary, customisation was applied.

In the process of developing the self-service application, users were involved in different ways and at different stages. From the start, several workgroups were formed.

The members of these groups were the end-users, inasmuch as they would actually use the application in their operational tasks. As part of their daily work, some members were also involved in the development of the application. One workgroup was involved in simplifying and standardising the HR processes. After 
24 processes had been defined, these became the bases to build the technical system that should support them. The workgroups were also involved in incorporating the right business rules within this system. An example of such a rule was calculating the maximum compensation that should be granted in different situations.

In the final part of building the application, a number of end-users were asked to test the application. This group of end-users did have knowledge on the processes that should be supported; however, they were not involved earlier during the development of the application. Per user-acceptance test session, seven to ten participants were asked to complete scenarios that were designed to guide them through a certain task. Users could comment not only on these tasks (for instance filing an expense claim) in general, but also on specific steps within the process. The grouped and summarised comments/findings were then discussed by the P-Direkt programme leaders and the builder of the application. During these discussions it was decided which findings needed fixing, and they were then fixed within two to three days. After that, new test sessions were held to examine whether or not the problems were sufficiently solved.

\subsection{Case 3: The Ministry of Health, Welfare and Sport}

Since 2007, within the Ministry of Health, Welfare and Sport, an e-HRM application called 'P-Loket' has been used. The application was actually co-developed with the Ministry of Social Affairs and Employment, because this ministry uses the same payroll application. P-Loket was designed as a web application, and functions as a layer on top of this payroll application (PersonnelView, or P-View). For the ministry and its employees, P-Loket was a totally new application. It was designed for employees to support them in (personnel) tasks, such as initiating a request for leave. In June 2007, around 12 different forms were supported by the application to be used by approximately 2250 civil servants.

These numbers should grow to about 18 forms and 5000 employees by January 2008.

The forms and processes that should be supported were chosen based on the outcomes of the standardisation workgroup of the P-Direkt project (see previous section).

The first quarter of 2006 was used as preparation period and to come up with a plan of how to approach the project. The second quarter of the year was used to prepare for the building, make a process design and setting up authorisations. By the end of June, the actual creation of the application could start. Building the application was done by an external software company that also created the P-View application. Although P-Loket was a new application, P-View was, in some cases, the main example to follow. One developer worked full-time on the project.

Employees of the Ministry were involved in several ways during the development.

The project group that was formed at the start consisted of HR employees, members of the audit service and two employees of the ICT department. The latter two were experts on web (applications) and usability. Both these experts had the task of looking at the application from a user perspective. The usability expert, along with the developer, reviewed a number of prototypes on screen. The project group focused on the business rules to be implemented. In addition, the application was demonstrated to different groups of three to twelve managers during five weeks. Managers could deliver feedback by addressing questions or remarks during the demonstration. Although this way of involving end-users took considerable time and effort, it was considered to be very useful and contributed to the acceptance of the application. One of the strengths of having different sessions was that certain issues came up. For example, the complexity of doing employee assessments was discussed thoroughly through the demonstrations, resulting in a consensus on how these meetings could be standardised and streamlined. The issues from the different sessions were combined, and for each issue the mean urgency was determined. Subsequently, the impact of the solutions on these issues was discussed with the software developer.

Users were also represented in the project group, and other civil servants were likewise asked to cooperate in usability testing. The main reason was to resolve usability issues, which the software developer and the usability expert from the project could not agree on. The tests took place in one room, while observers were in another room to take notes and film the session with a camera. In total, eight users were selected taking into account their computer skills, the male/female ratio and office/field staff ratio within the group. The PLoket project group was located in the same offices as the end-users. This provided the opportunity to ask these users their opinions in an informal ad hoc way, which the project group gratefully used during the development of P-Loket. 


\subsection{Case 4: The Ministry of Defence}

The Ministry of Defence started implementing a self-service application for HR processes in 2004. The application was based on the PeopleSoft HR system. The first processes to be supported concerned access to personal data, filing requests for leave and foreign travel. Approximately 80000 users make use of the software, of which about 65000 are permanent staff. Owing to frequent shifts within the organisation (for instance, staff being posted abroad for military operations) the application should offer the possibility of delegating certain tasks to other superiors, planners and/or secretaries.

Because many users had wrong interpretations about the application, the ministry started improving the self-service parts of the application in 2006. It took about one-and-a-half years until the improved application went live, mainly dedicated to determine which people and processes should actually be supported. Subsequently the possibilities of the application were (re)investigated. The main rationale behind this was that the development should not only be seen as supporting a process by an application, but also supporting users in their actions when using the application.

Usability research was executed by professionals from outside the Ministry who had no knowledge of HR processes or PeopleSoft. Some consultancy was done by external parties, but it seemed most of the work to come up with advice and reports was done by the internal organisation.

Users were involved not only in usability research, but also in other ways. Employees with IT knowledge and skills were asked to identify functional gaps in the support of certain processes. Next to that, case studies were done by randomly asking people in the organisation to perform tasks with the application. After a short introduction (and the reassurance that they could do nothing wrong), inexperienced users were observed completing the tasks while they were invited to think aloud. The moments when users hesitated or were in doubt were explained as moments in the process when the application should offer help. One of the standard tools for help within the PeopleSoft application was the 'See, Try, Know, Do' principle. Users can first look at a demonstration (see) before trying it themselves in a simulation mode (try). A next step was then to take a test to check if they understood everything (know), before finally actually performing the task with the application (do). Users can use one or more of these functions to support them.

with different ICT skills. From the test/think aloud sessions, it was concluded that demands for support and help options significantly differ by the ICT skills of the end-user. In addition, to (re)confront users with the improved application, the development process was accompanied with prototypes as well.

\section{CROSS-CASE COMPARISON ANALYSIS}

The previous case studies show that users were involved and were enabled to participate in the development of the ESS-systems in different ways. For the cross-case analysis, we categorise the actions for each case according to the three categories of user participation methods as presented in Section 2. Because we specifically want to explore the (expected positive) effects of user participation, we also collected information about the perceived success of the ESS applications for each case study. For this purpose, a short (mail) survey was sent out to the interviewees. They were requested to indicate the following criteria on a five-point scale:

- $\quad$ The number of problems reported by users in the user (acceptation) tests (ranging from 1 being 'very few' to 5 being 'seriously many').

- - The amount of rework needed after testing (ranging from 1 being 'very little' to 5 being 'very much').Although all interviewees replied in the survey, we should note that this is an indication of their perceived success of the ESS deployment (i.e., not the ultimate evaluation of each of the projects). The user participation methods and the perceived success of the four case studies are jointly presented in Table 1.

\section{[TABLE 1]}

From Table 1, we see that in all cases end-users have participated in one or more tests during the development. In two cases, prototypes were used to let users judge (parts of) the application earlier in the process of development. The ESS application at the Ministry of Defence was accompanied with most of the different user participation methods, including use research.

It is quite interesting to see from Table 1 as well, that the relationship between user participation method(s) and the perceived ESS-deployment success is far from obvious. 
While in the case of the Ministry of the Interior and Kingdom Relationships and the Ministry of Internal Affairs testing was the only user participation method applied, their success in terms of reported problems and rework differ significantly. In the case of the Ministry of Defence, one would expect low scores on the two 'failure' indicators - instead it was judged that this case scores about average on its level success. This result calls for a further investigation of the other conditions for the relationship between user participation and IS/IT project success. This will be elaborated in the next and closing section.

\section{CONCLUSIONS AND DISCUSSION}

This paper departed from the concepts of user involvement and user participation and several studies that demonstrated a positive relationship between user participation, involvement and system success. We performed four case studies based on interviews with stakeholders from four Dutch ministries that recently (re)developed and deployed an ESS application. In all cases, the ESS application was introduced to improve the efficiency of a number of HRM processes by enabling employees to register, request and monitor their contractual labour relations and benefits, such as holidays and leaves.

In line with the literature, one would expect that ministries/projects in which users participated early in the development were more successful than the ones that applied less types of user participation. The case studies showed, however, that this relation was not this self-evident. The case of the Ministry of Defence illustrates this conclusion: many different user participation methods were applied, but still many problems and much rework was perceived during the deployment of the ESS application.

Hence, we should recognise that conditions for the success of user participation and IS/IT deployment play an important role. From the case studies performed, it was found that two conditions are crucial: time and culture.

With regard to time, it is important to realise that soliciting input from users may cause delay to the project. It is necessary to set deadlines when decisions need to be made, otherwise endless discussions might arise and requirements will keep changing.

This was particularly noticed in the case of Emplaza at the Ministry of Interior and Kingdom Relationships. Testing was done on an extensive basis, but the promised application was heavily delayed and therefore lost 'momentum' in the organisation.

Expectancy management is crucial to tell participating users what will be done with their input and why. Not all of their suggestions and problems might be implemented or solved. To ensure that they continue to be willing to cooperate, it is important to communicate why certain decisions have been made and why some of their input are not visible in the developed application.

Culture was another relevant condition in the ESS projects studied. Although users within the Ministry of Defence were involved in three different ways, test persons were not used to giving feedback on their perceptions of IS/IT system or how processes should look like. In all cases it generally matters to have the development team close to the end-users, preferably on location. This enables more frequent consultation between end-users and developers, concerning for instance uncertainties about requirements or just asking user's opinions on what has been developed thus far. Being able to follow the progress did positively influence the involvement of end-users, most prominently in the case of the Ministry Of Health, Welfare and Sport.

Finally, a number of additional lessons can be mentioned. With regard to specific IS/IT as ESS applications, one should specifically keep in mind that employees should be able to use the self-service applications without too much support from the HR departments. Otherwise it would produce the (sceptic) attitude that the ESS deployment only implies a shift of the workload for the HR department from HR tasks to the employees as users of the application. Another important aspect to take into account is the complex decision processes within governmental organisations, such as ministries.

Both technological and organisational decisions are strongly influenced by many different stakeholders, take considerable time and are also politically oriented.

\section{REFERENCES}

Barki, H. and Hartwick, J. (1989) 'Rethinking the concept of user involvement', Rethinking the Concept of User Involvement, Vol. 13, No. 1, pp.53-63. 
Baroudi, J.J., Olson, M.H. and Ives, B. (1986) 'An empirical study of the impact of user involvement on system usage and information satisfaction', Communications of the ACM, Vol. 29, No. 3, pp.232-238.

Beyer, H. and Holtzblatt, K. (1999) 'Contextual design', Interactions, Vol. 6, No. 1, pp.32-42.

Blackburn, J., Scudder, G. and Van Wassenhove, L.N. (2000) 'Concurrent software development', Communications of the ACM, Vol. 43, No. 11, pp.200-214.

Blomberg, J., Giacomi, J., Mosher, A. and Swenton-Hall, P. (1993) 'Ethnographic field methods and their relation to design', in D. Schuler and A. Namioka (Eds.) Participatory Design: Principles and Practices, Hillsdale: Lawrence Erlbaum, pp.123-155.

Blomquist, Å. And Arvola, M. (2002) 'Personas in action: ethnography in an interaction design team', Proceedings of the Second Nordic Conference on Human-Computer Interaction, pp.197-200.

Chatzoglou, P.D. and Macaulay, L.A. (1996) 'Requirements capture and analysis: a survey of current practice', Requirements Engineering, Vol. 1, pp.75-87.

Cherry, C. and Macredie, R.D. (1999) 'The importance of context in information system design: an assesment of participatory design', Requirements Engineering, Vol. 4, No. 2, pp.103-114.

Damodaran, L. (1996) 'User involvement in the systems design process-a practical guide for users', Behaviour \& Information Technology, Vol. 15, No. 6, pp.363-377.

DeLone, W.H. and McLean, E.R. (1992) 'Information system success: the quest for the independent variable', Information Systems Research, Vol. 3, No. 1, pp.60-95.

DeLone, W.H. and McLean, E.R. (2003) 'The DeLone and McLean model of information success: a tenyear update', Journal of Management Information Systems, Vol. 19, No. 4, pp.9-30.

Fister Gale, S. (2003) 'Three stories of self-service success', Workforce, Vol. 82, No. 1, pp.60-63.

Gould, J.D. and Lewis, C. (1985) 'Designing for usability: key principles and what designers think', Communications of the ACM, Vol. 28, No. 3, pp.300-311.

Grudin, J. (1991) 'Systematic sources of suboptimal interface design in large product development organization', Human Computer Interaction, Vol. 6, No. 2, pp.147-196.

livari, N. (2006) 'Representing the user' in software development - a cultural analysis of usability work in the product development context', Interacting with Computers, Vol. 18, pp.635-664.

Ives, B., Olson, M.H. and Baroudi, J.J. (1983) 'The measurement of user information satisfaction', Communications of the ACM, Vol. 26, No. 10, pp.785-793.

Janssen, M. and Joha, A. (2006) 'Motives for establishing shared service centers in public administrations', International Journal of Information Management, Vol. 26, No. 2, pp.102-115.

Kensing, F. and Blomberg, J. (1998) 'Participatory design: issues and concerns', Computer Supported Cooperative Work, Vol. 7, Nos. 3-4, pp.167-185.

Konradt, U., Christophersen, T. and Schaeffer-Kuelz, U. (2006) 'Predicting user satisfaction, strain and system usage of employee self-services', International Journal Human Computer Studies, Vol. 64, No. 11, pp.1141-1153.

Kujala, S. (2003) 'User involvement: a review of the benefits and challenges', Behaviour \& Information Technology, Vol. 22, No. 1, pp.1-16.

Lin, W.T. and Shao, B.B. (2000) 'The relationship between user participation and system success: a simultaneous contingency approach', Information \& Management, Vol. 37, No. 6, pp.283-295.

Littlejohn, S.W. (2002) Theories of Human Communication, Belmont: Wadsworth/Thomson Learning.

Mantei, M.M. and Teorey, T.J. (1988) 'Cost/Benefit analysis for incorporating human factors in the software lifecycle', Communications of the ACM, Vol. 31, No. 4, pp.428-439.

McKeen, J.D. and Guimaraes, T. (1997) 'Successful strategies for user participation in systems development', Journal of Management Information Systems, Vol. 14, No. 2, pp.133-150.

McKeen, J.D., Guimaraes, T. and Wetherbe, J.C. (1994) 'The relationship between user participation and user satisfaction: an investigation of four contingency factors', MIS Quarterly, Vol. 18, No. 4, pp.427-451.

Muller, M. (2001) 'A participatory poster of participatory methods', Conference on Human Factors in Computing Systems, CHI '01 Extended Abstracts on Human Factors in Computing Systems, pp.99-100. Nielsen, J. (1993) Usability Engineering, San Diego: Academic Press.

Nielsen, J. and Mack, R.L. (Eds.) (1994) Usability Inspection Methods, New York, NY: John Wiley \& Sons. Noyes, P.M., Starr, A.F. and Frankish, C.R. (1996) 'User involvement in the early stages of an aircraft warning system', Behaviour \& Information Technology, Vol. 15, No. 2, pp.67-75.

Ruël, H., Bondarouk, T. and Looise, J.K. (2004) 'E-HRM: innovation or irritation. An explorative empirical study in five large companies on web-based HRM', Management Revue, Vol. 15, No. 3, pp.364-380.

Shapiro, D. (2005) 'Participatory design: the will to succeed', Proceedings of the 4th Decennial Conference on Critical Computing: Between Sense and Sensibility, Aarhus, Denmark, pp.29-38.

Shaw, N.C., DeLone, D.H. and Niederman, F. (2005) 'Sources of dissatisfaction in end-user support: an empirical study', The DATA BASE for Advances in Information Systems, Vol. 33, No. 2, pp.41-56. 
Batenburg, R., Koopman, G. The conditional benefits of early user involvement at employee self-service applications in four Dutch ministries. International Journal of Business Information Systems: 2010, 5(2),162 174

Simonsen, J. and Kensing, F. (1997) 'Using ethnography in contextural design', Communications of the ACM, Vol. 40, No. 7, pp.82-88.

Strohmeier, S. (2007) 'Research in e-HRM: review and implications', Human Resource Management Review, Vol. 17, No. 1, pp.19-37.

Wharton, C., Polson, P., Lewis, C. and Rieman, J. (1992) 'Cognitive walkthroughs: a method for theorybased evaluation of user interfaces', International Journal of Man-Machine Studies, Vol. 36, pp.741-773.

\section{BIBLIOGRAPHY}

Butler, M.B. (1996) 'Getting to know your users: usability roundtables at Lotus Development', Interaction, Vol. 3, No. 1, pp.23-30.

Clement, A. and Van den Besselaar, P. (1993) 'A retrospective look at PD projects', Communications of the ACM, Vol. 36, No. 4, pp.29-37.

Davis, F.D. (1989) 'Perceived usefulness, perceived ease of use, and user acceptance of information technology', MIS Quarterly, Vol. 13, No. 3, pp.319-340.

Gibson, H. (1977) 'Determining user involvement', Journal of System Management, pp.20-22.

Ives, B. and Olson, M.H. (1984) 'User involvement and MIS success: a review of research', Management Science, Vol. 30, No. 5, pp.586-603.

Lucas, H.J. (1974) 'Systems quality, user reactions, and the use of information systems', Management Informatics, Vol. 3, No. 4, pp.207-212.

Mason, R.O. (1978) 'Measuring information output: a communication systems approach', Information \& Management, Vol. 1, No. 4, pp.219-234.

Pekkola, S., Niina, K. and Pasi, P. (2006) 'Towards formalised end-user participation in information systems development process: bridging the gap between participatory design and ISD methodologies',

Proceedings of the Ninth Participatory Design Conference 2006, pp.21-30.

Robey, D. and Farrow, D. (1982) 'User involvement in information system development: a conflict model and empirical test', Management Science, Vol. 28, No. 1, pp.73-85.

Rowley, D.E. (1996) 'Organizational considerations in field-oriented product development: experiences of a cross-functional team', in D. Wixon and J. Ramey (Eds.) Methods Casebook for Software Design, New York: Wiley, pp.125-144.

Saarinen, T. (1996) SOS An expanded instrument for evaluating information system success. Information \& Management, Vol. 31, No. 2, pp.103-118.

Shannon, C.E. and Weaver, W. (1949) The Mathematical Theory of Communication, Urbana: University of Illinois Press.

\section{TABLE}

Table 1 Methods used to involve end-users and perceived failure/success for the four cases under investigation

\begin{tabular}{|c|c|c|c|c|c|}
\hline \multirow[b]{2}{*}{ Case } & \multicolumn{3}{|c|}{ User participation method } & \multicolumn{2}{|c|}{$\begin{array}{c}\text { Perceived failure/success } \\
\text { of the project }\end{array}$} \\
\hline & Prototypes & Testing & $\begin{array}{c}\text { Use- } \\
\text { research }\end{array}$ & $\begin{array}{c}\text { Reported problems } \\
\text { after test }\end{array}$ & $\begin{array}{l}\text { Amount of } \\
\text { rework needed }\end{array}$ \\
\hline $\begin{array}{l}\text { 1. The Ministry } \\
\text { of the Interior and } \\
\text { Kingdom Relationships }\end{array}$ & & $\mathrm{x}$ & & 5 & 5 \\
\hline $\begin{array}{l}\text { 2. The Ministry of } \\
\text { Internal Affairs }\end{array}$ & & $\mathrm{x}$ & & 2 & 1 \\
\hline $\begin{array}{l}\text { 3. The Ministry of Health, } \\
\text { Welfare and Sports }\end{array}$ & $\mathrm{x}$ & $\mathrm{x}$ & & 2 & 4 \\
\hline 4. The Ministry of Defence & $\mathrm{x}$ & $\mathrm{x}$ & $\mathrm{x}$ & 3 & 4 \\
\hline
\end{tabular}

